\title{
Introducing Research-based Instructional Strategies in a Rural Engineering College in India
}

\author{
Dr. Pradeep Kashinath Waychal, Guruji Education Foundation
}

Dr Pradeep Waychal is a founder trustee of Guruji Education Foundation that provides holistic support to the higher education of underprivileged students and a visiting professor of Engineering Education at CRICPE of Western Michigan University, US. Earlier, Dr Waychal has worked at Patni Computer Systems for 20 years in various positions including the head of innovations, NMIMS as the director Shirpur campus, and at College of Engineering Pune (COEP) as the founder head of the innovation Center.

Dr Waychal earned his Ph D in the area of developing Innovation Competencies in Information System Organizations from IIT Bombay and M Tech in Control Engineering from IIT Delhi. He has presented keynote / invited talks in many high prole international conferences and has published papers in peerreviewed journals. He / his teams have won awards in Engineering Education, Innovation, Six Sigma, and Knowledge Management at international events. His current research interests are engineering education, software engineering, and developing innovative entrepreneurs and intrapreneurs. He has been chosen as one of the five outstanding engineering educators by IUCEE (Indo-universal consortium of engineering education).

\section{Prof. Jayantrao Bhaurao Patil, R. C. Patel Institute of Technology, Shirpur, India}

Jayantrao B. Patil is working as the Principal at the R. C. Patel institute of Technology, Shirpur, India and holds appointment as a Professor in the Department of Computer Engineering. He is also serving as a Dean, Faculty of Engineering and Technology, Member of Senate, Member of Academic Council, and Chairman of Board of Studies in Computer Engineering \& Information Technology at the North Maharashtra University, Jalgaon, India.

Jayantrao's research interests include Web caching, Web Prefetching, Web data mining, Biometrics, and digital watermarking. He is the author/co-author of over 10 papers in refereed journal publications and over 10 papers in conference proceedings. He is also associated with many international conferences like ICICT 2014 at Chengdu, China, ICICT 2013 at New Delhi, India, and DNCOCO 2007 at Port of Spain, Trinidad and Tobago as a Session Chair and Program Committee Chair.

\section{Dr. Pramod Jagan Deore, R.C. Patel Institute of Technology, Shirpur, India}

Pramod Deore is Professor of Electronics and Telecommunication Department at the R. C. Patel Institute of Technology, Shirpur, India. He is also serving as a Senate Member and Member of Board of Studies in Electronics and Telecommunication at the North Maharashtra University, Jalgaon, India. His research interests include Interval arithmetic operations applications in Robust Control, Image Processing, and Biomedical Signal Processing etc. He has published 40 papers in National/International Conferences/Journals and he has Co-authored two books. He is Member of IEEE and life member of ISTE

\section{Mr. Dharmaraj Rajaram Patil, R. C. Patel Institute of Technology, Shirpur, India}

Dharmaraj Rajaram Patil has completed his master of engineering in computer science \& engineering, Government College of Engineering, Aurangabad, Maharashtra, India in 2010 and pursuing his Ph.D. in computer engineering from North Maharashtra University, Jalgaon, Maharashtra, India. He is working as an assistant professor in the Information Technology Department at R.C. Patel Institute of Technology, Shirpur (Maharashtra), India. He has 13 years of teaching experience. 


\section{Introducing research-based instructional strategies in a rural engineering college in India}

\section{Introduction}

Promoting broader use of research-based instructional strategies (RBIS) is a critical challenge in undergraduate engineering education [1]. Marzano et al. [2] quote work of Sanders and colleagues that analyzed more than 100,000 students across 1,000 schools to conclude that teachers are the principal factors in students' learning and also found that teachers can improve their effectiveness by using proven instructional strategies. In the recent times, many educators and researchers have proven utility of such proven strategies i.e. research-based instructional strategies (RBIS) [3, 4].

A good educational institution, therefore, must focus on the use of research-based instructional strategies (RBIS). Brent and Felder have designed the Southeastern University and College Coalition for Engineering Education (SUCCEED) model that focuses on faculty's instructional skills [5]. They have been also conducting faculty development workshops under the auspices of 'The National Effective Teaching Institute' (NETI), which have proved to be hugely successful [6]. Such development efforts need to intensify across the globe, especially because the engineering education researchers have been developing a host of instructional strategies and educators have been significantly lagging in using them[1]. In fact, Henderson and Dancy [7] argue that the improvement in engineering education lies not in finding more effective instructional strategies but in using the proven strategies.

This paper describes our attempt to introduce a few RBIS in a rural Indian engineering college. We introduced simple strategies such as using audio-visuals, think-pair-share, formative feedback, problem-based learning in lab sessions, and project-based learning in design courses in a one-day workshop. Eighty faculty members, in two batches, attended the workshop, which itself used many of the above RBIS. The participating faculty members reflected on the strategies in groups and developed their implementation plans for the subsequent semester. The first author mentored the workshop participants over the Skype calls, WhatsApp groups, and emails; while other authors conducted in-person review sessions.

At the end of the semester, we administered a survey to the faculty members, who had submitted their implementation plans, to understand their perception of the success of the plan. The institute administrators interviewed them to validate the success stories. For the faculty members, whose success stories were validated and who had taught the same course in the earlier year, we compared the SETs (Student evaluation of teachings) of the current (post-workshop) and earlier years (preworkshop), and found statistically significant improvement. The paper discusses the workshop design and results' analysis in the next sections, and ends with concluding remarks.

\section{Workshop Design}

A discussion between the first author (an external educator) and other authors (the administrator, his deputy, and a senior professor of the institute) led to the decision of conducting an interactive workshop on the use of research-based instructional strategies for faculty members of the 
institute. The institute is in a tier-3 city (a small town), is affiliated to a regional university, and is doing extremely well in academics. It has been capturing most of the top university ranks and reporting the highest percentage of passing among all the engineering colleges of the university. It employs 127 faculty members, admits around 600 students every year, and offers various courses such as Mechanical Engineering, Electronics \& Telecommunication Engineering, Computer Engineering, Information Technology, Civil Engineering, and Electrical Engineering. More than $50 \%$ of the students are first-generation college learners and more than $80 \%$ students belong to farmers or laborer family i.e. have lower socio-economic background. Further, most of the students' K-12 medium of instruction is their native language and at the college, it is English.

The workshop objective was to influence teaching practices of the college faculty and the outcomes were, participating faculty should be able to explain the current engineering education scenario and the critical need of RBIS, be able to explain the RBIS covered in the workshop, and be able to apply them to create better learning experience for their students. The first author identified the strategies to be covered and designed the workshop (Figure 1).

1. The workshop started with aligning participants' expectations, and discussing objectives and outcomes of the workshop.

2. Then we covered $3 \mathrm{H}$ (head, heart and hand) model and the importance of RBIS. Sipos et al. have used the organizing principle of head, hands and heart [8]. Our 3H model was developed on similar lines.

3. For each RBIS, the workshop faculty provided basic information, possible configurations (changes that individuals may do while implementing the strategies), and choregraphing details (how exactly the RBIS may be used). The participants formed teams to reflect on the benefits and obstacles. This structure was based on Henderson et al.'s guide [9].

4. Reichert and Absher [10] have aptly said that it's not so much the details of what successful programs do, rather it's the care with which they do it. Therefore, we emphasized the importance of passion in deploying the RBIS.

5. We then explained the challenges in implementating any new ideas based on Rogers's work on innovation diffusion[11].

6. The particiapants chose around three strategies to use in the subsequent semester and organized department-wise discussion on the plans.

7. All the departments pressented their collective plans to the entire cohort.

8. We closed the workshop by discussing their takeaways and seeking the end-of-workshop evaluations.

9. To track progress and address roadblocks, the institiute authors followed up with the participants on a regular basis. The first author (workshop faculty) joined the discussion over the Skype calls. We also floated a whatsapp groups for faculy to discuss their expereinces. Henderson [9] has highlighted importance of such support.

The overall feedback of the workshops based on Reichheld's net promoter score concept [12] on the Likert scale was 4.5/5.

\section{Results}

Out of the eighty faculty members, who participated in two iterations of the workshop, fifty-eight (seventy-three percent) submitted plans for using RBIS (Appendix A has a sample plan). Table 1 provides the number of faculty members who chose different RBIS in their plans. Henderson et 
al. [13] surveyed faculty on knowledge and use of RBIS and found that $87.1 \%$ faculty were familiar with one or more RBIS, but only $48.1 \%$ used an RBIS. Froyd et al. [1] found awareness of RBIS to be very high, but reported the use in the range of $10 \%$ to $70 \%$, depending on characteristics of the strategy.
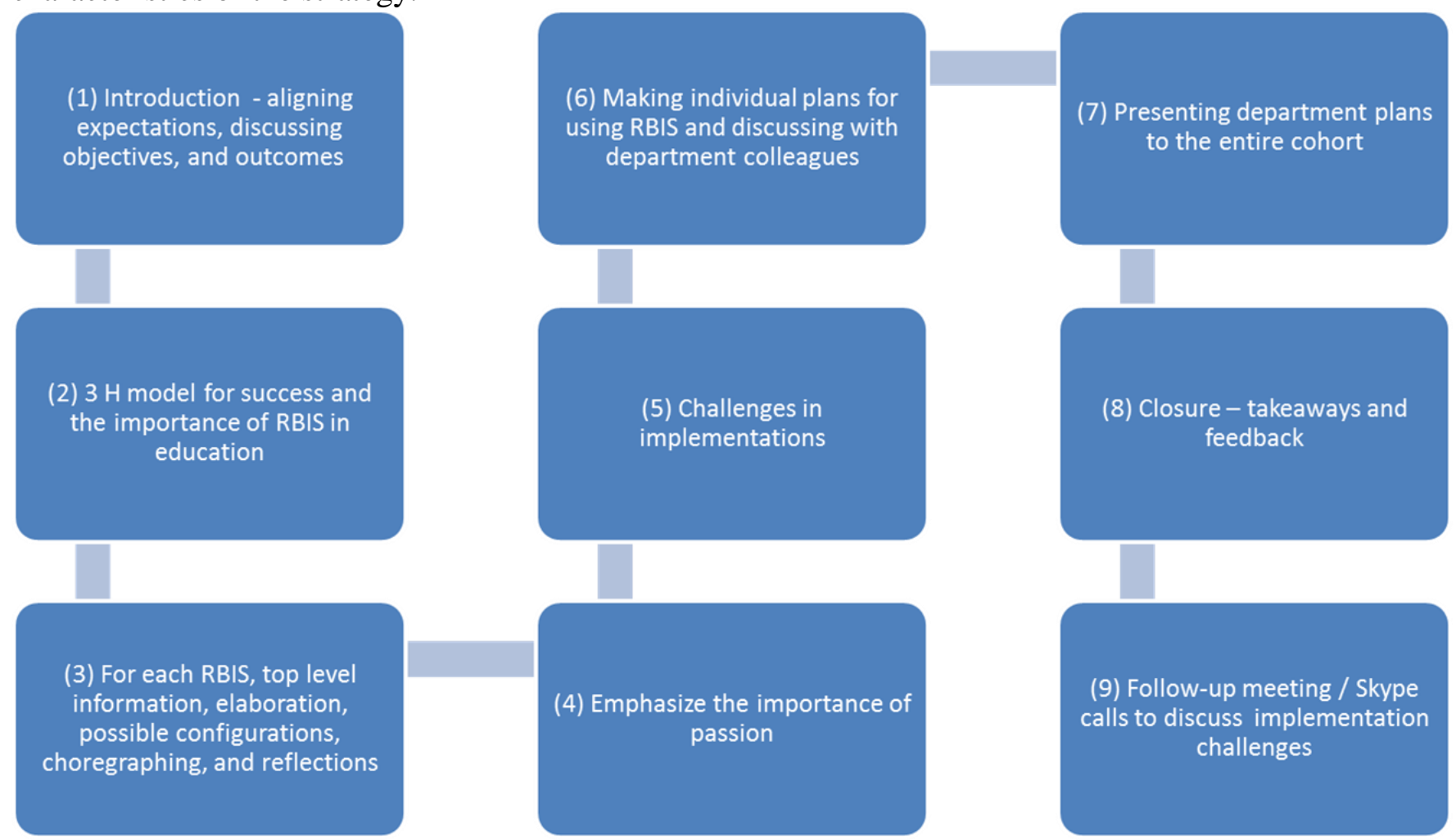

Figure 1: Workshop Design

Table 1. RBIS chosen by faculty members for implementation

\begin{tabular}{ccc}
\hline RBIS & $\begin{array}{c}\text { No. of Faculty who chose } \\
\text { the RBIS }\end{array}$ & $\begin{array}{c}\text { \% of Faculty who chose the } \\
\text { RBIS }\end{array}$ \\
\hline Audio-Video & 38 & $66 \%$ \\
\hline Formative Feedback & 26 & $45 \%$ \\
\hline Think Pair Share & 24 & $41 \%$ \\
\hline Lab Sessions & 14 & $24 \%$ \\
\hline Project Based Learning & 2 & $3 \%$ \\
\hline
\end{tabular}

Towards the end of the semester, we administered an anonymous survey to the participants who had submitted their plans, asking difficulties they faced in using their chosen RBIS, the most important thing in implementing their chosen RBIS, and their plan to implement RBIS in the next 
semester. Thirty-two of the fifty-eight participants responded. The most common reported difficulty was time constraints $(69 \%)$, followed by students not participating $(13 \%)$, and large class-sizes $(9 \%)$. The most important things in implementing RBIS were staff motivation (34\%) and publicizing success stories on social media (25\%). Finelli et al. have accorded the importance to faculty motivation in adopting effective teaching practices [14, 15]. All 32 faculty members, who responded to the survey were planning to implement RBIS in the next semester. We administered another survey to understand perception of faculty members on the success of implementing their plans and received responses from 41 faculty members. All of them believed that they were successful in implementing their plans.

Out of the 41 faculty members, 29 faculty members taught the same course in the earlier semester. While between the instructor and the course; the instructor has more influence on the student evaluation, the course influence cannot be ignored [16]. Therefore, we analyzed performance of only those faculty members who had taught the same course in the earlier year. The administrators interviewed the 29 faculty members and concurred with 22 faculty members' beliefs.

We compared student evaluation of teaching (SET) of those 22 faculty members with their earlier year's SETs and found statistically significant difference $(p=0.029)$. We have provided the course names, the SETs of 2015-16 and 2016-17, and the change direction (for better or worse) in table 2. We have provided scatter plot of the SETs in figure 3. While seventeen courses had better SETs, five had worse in 2016-17 as compared to 2015-16.

We used SET as the measure of the success for using the strategies. While Shvelin et al. found that student ratings do not wholly reflect actual teaching effectiveness. [17], Benton and Cashin's [18] and Richardson's [19] SET literature review indicated otherwise. Benton and Cashin concluded their review by stating that student ratings tend to be statistically reliable, valid, and relatively free from bias or the need for control, perhaps more so than any other data used for faculty evaluation. We, therefore, decided to use the SET and did not check the validity and reliability of the SET data.

Figure 2 depicts the declines in the number of faculty members from attending the workshop to the successful deployment of the RBIS. The decline from 80 attendees to 58 plans and from 58 plans to 41 self-assessments of successful deployment are not encouraging, however, are in line with the findings of other researchers as discussed earlier. The statistically significant improvement in SETs of the faculty, who had successfully deployed the learning strategies is encouraging. 


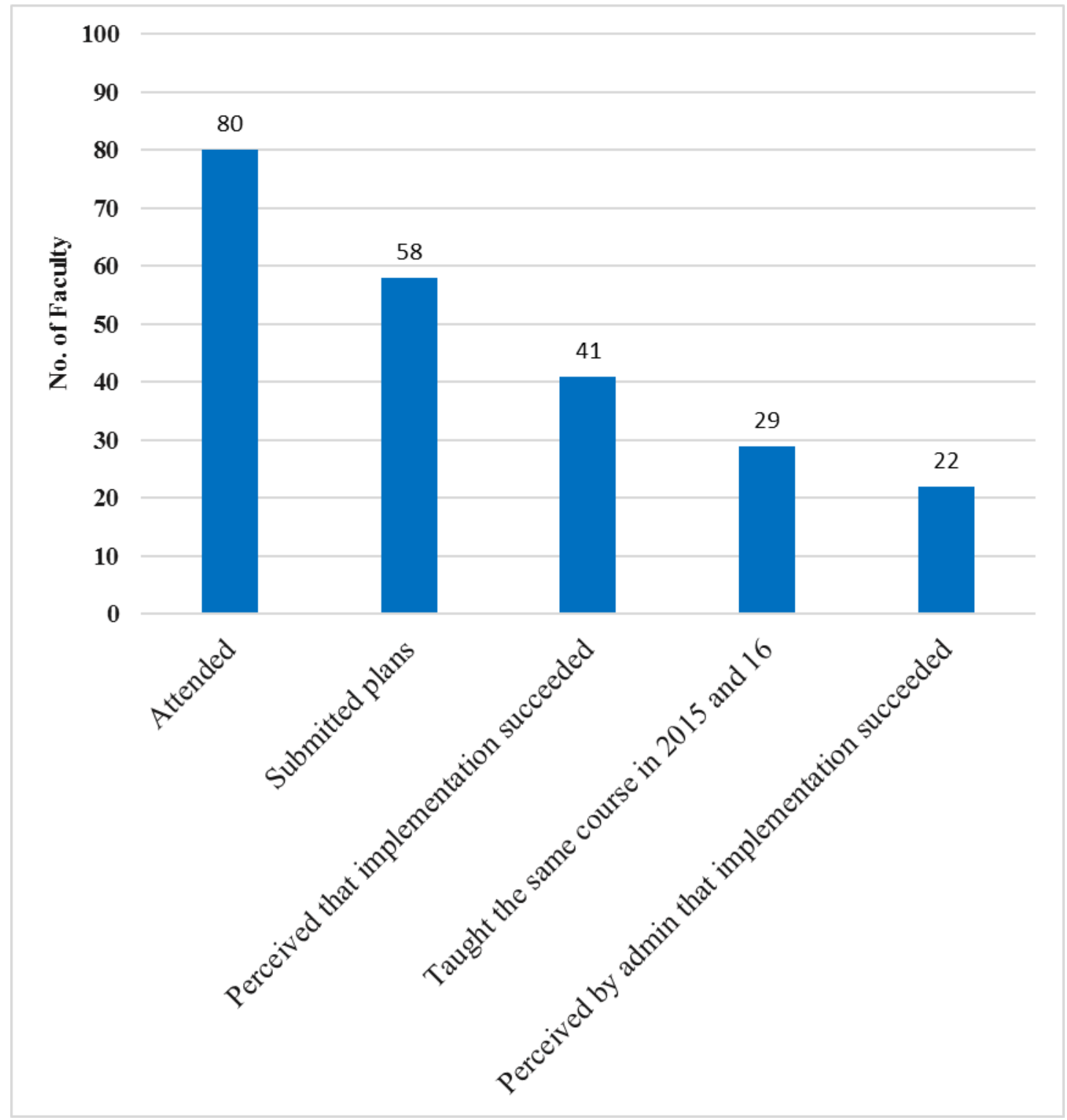

Figure 2 Participation in the workshop to successful implementations 
Table 2. SET Analysis for 2015-16 and 2016-17

\begin{tabular}{lccl}
\hline \multicolumn{1}{c}{ Course } & $\mathbf{2 0 1 5 - 1 6}$ & $\mathbf{2 0 1 6 - 1 7}$ & SET Change \\
\hline Android Programming - Computer & 9.16 & 8.76 & Worse \\
\hline Android Programming - IT & 8.44 & 9.09 & Better \\
\hline Communication System & 7.83 & 9.34 & Better \\
\hline Component Devices \& Instrumentation Technology & 8.63 & 9.49 & Better \\
\hline Computer Communication & 8.29 & 9.45 & Better \\
\hline Computer Network & 8.18 & 7.76 & Worse \\
\hline Discrete Structure and Graph Theory & 8.62 & 9.27 & Better \\
\hline Electrical Circuit and Machine & 8.77 & 9.50 & Better \\
\hline Electromagnetic Engineering & 9.27 & 9.42 & Better \\
\hline Electronic Circuit Design & 9.15 & 9.23 & Better \\
\hline Engineering Thermodynamics & 8.90 & 9.15 & Better \\
\hline Fiber Optics Communication & 7.03 & 8.25 & Better \\
\hline Heat Transfer & 9.04 & 9.35 & Better \\
\hline Manufacturing Engineering - I & 7.50 & 7.75 & Better \\
\hline Material Science and Metallurgy & 8.70 & 8.55 & Worse \\
\hline Power Electronics - Division 1 & 9.00 & 8.99 & Worse \\
\hline Power Electronics - Division 2 & 9.25 & 9.4 & Better \\
\hline Solid State Devices \& Circuits-I & 9.15 & 9.46 & Better \\
\hline Structure Design I - Division 1 & 8.47 & 8.87 & Better \\
\hline Structure Design I - Division 2 & 8.42 & 8.97 & Better \\
\hline Theory Machines-II & 8.48 & 8.25 & Worse \\
\hline Very Large Scale Integration Design & 8.20 & 8.72 & Better \\
\hline Average & $\mathbf{8 . 5 7}$ & $\mathbf{8 . 9 6}$ & \\
\hline
\end{tabular}




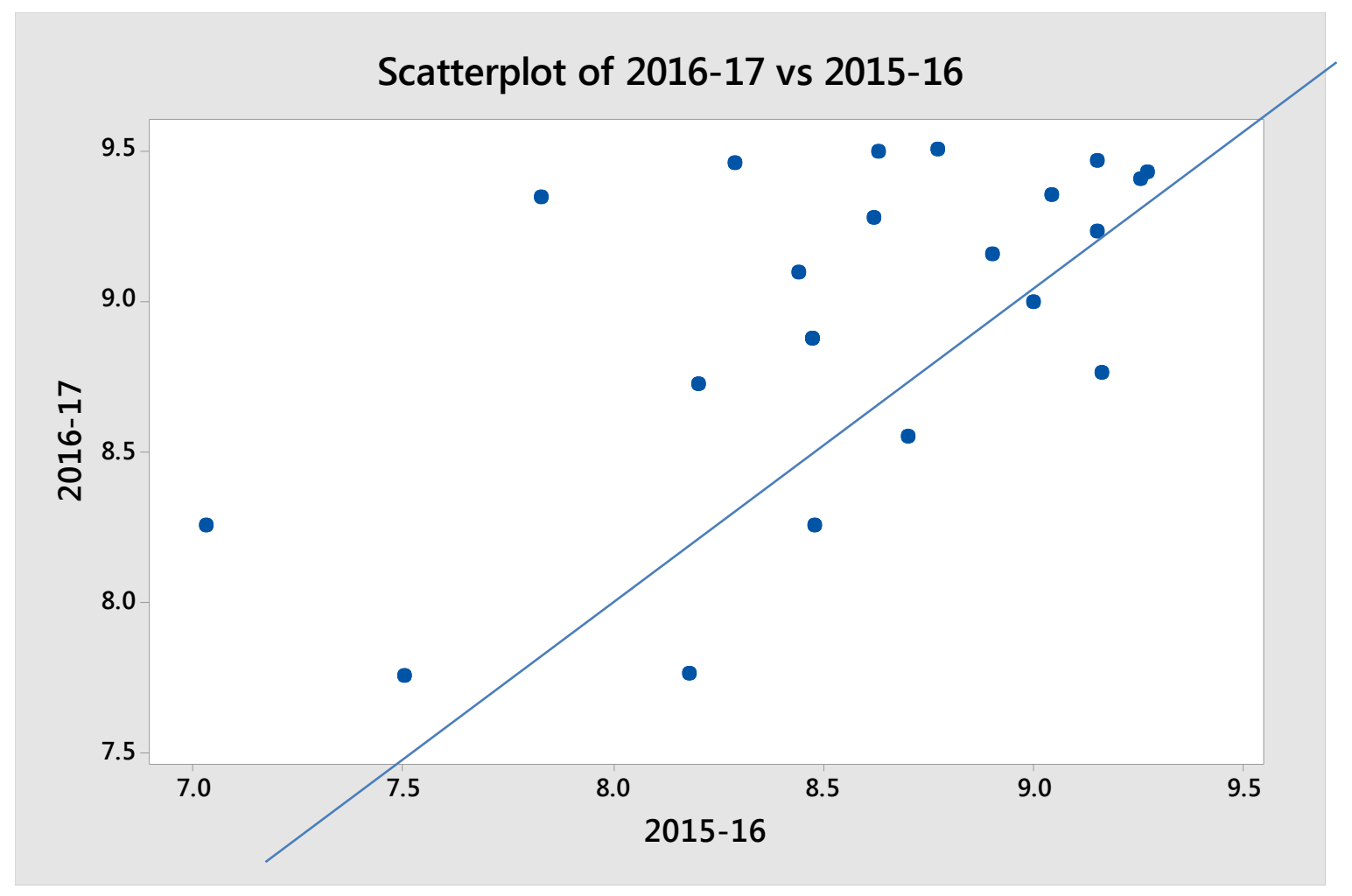

Figure 3: Scatter plot of the SET of 2015-16 and 2016-17

(The line is a no change line - the points above the line indicate positive changes and the ones below indicate negative changes)

\section{Concluding remarks}

Even though RBIS have convincingly proven their value, their adoption is far from satisfactory. This paper describes our experience of deploying RBIS at a rural but a reputable Indian engineering college. In two iterations of a daylong workshop, we introduced a few strategies to 80 faculty members. Even though most of them liked the workshop (as indicated by the overall rating of $4.5 / 5)$, only 58 out of 80 attendees $(73 \%)$ submitted their plans to implement the discussed RBIS, and only 41 out of those $58(81 \%)$ claimed successful implementations. These numbers are in the proximity of the earlier reported numbers [1, 13], and underline the challenges posed in deploying RBIS. Out of the 41, 29 faculty members had taught the same courses in the earlier year (2015 fall), with whom we discussed their implementations, and adjudged 22 implementations as successful. We compared 2015 and 2016 SETs of the 22 faculty members and found statistically significant $(\mathrm{P}=0.029)$ increase in the 2016 SETs.

Many faculty members perceived the use of RBIS as time consuming. Froyd et al. [1], Prince et al. [20], and Felder and Brent [3] have reported similar faculty perceptions. To save class time, Felder and Rebecca have suggested providing handouts of information-based material and not covering that in the style of traditional lectures. We implemented the technique in our workshop itself and strongly recommended participants to use it. Those solutions seemed to have only limited success. 
Most of the college students are from lower socio-economic background, which hampers their communication abilities and resultant participation in classes that follow active learning strategies such as think-pair-share. We had suggested that the students with such difficulties be allowed to use their first languages. We must analyze the problem further and research better solutions.

We believe that more in-person mentoring by the workshop author could have increased the use of RBIS and the resultant teaching performance. Henderson and Dancy [21] and Henderson et al. [9] view the lack of support as a key reason for the poor use of RBIS. Brent and Felder's [5] SUCCEED model includes community of practices. We introduced a WhatsApp group for collaboration among workshop participants, but did not see enough activity on that. More efforts to stimulate the group could have been beneficial. While the institute administrators provided full support to the program, their active participation could have been another useful lever. We used the student evaluation of teaching (SET) to decide effectiveness of the use of RBIS. While the SET is regarded as the best measure of faculty's teaching performance, it cannot be the only measure [18]. We require using other measures such as peer feedback and students' learning outcomes. We plan to work on these steps in the next iteration of the experiment.

We can also analyze the result of use of different RBIS. Some strategies or some combination of strategies may be more fruitful than others. Besides, we can analyze correlation between faculty members and courses, and use of various strategies. Some faculty members' characteristics such as past performance, gender, experience in teaching the course and course characteristics such as course class size, course type (design, management, etc.), and course levels (freshmen, sophomore, etc.) may have some influence on outcomes.

We do realize the herculean task of improving the use of research-based instructional strategies among engineering faculty, in general and the Indian engineering faculty, in particular. We believe that we have made a good start that could pave the way for our success as well as help others in similar situations.

\section{Acknowledgements}

We thank all the faculty members who participated in the workshop and the management who funded the workshop. We also thank the division chair, Dr. Springer, and anonymous reviewers for their valuable comments.

\section{References}

1. Froyd, J.E., et al., Estimates of Use of Research-Based Instructional Strategies in Core Electrical or Computer Engineering Courses. Education, IEEE Transactions on, 2013. 56(4): p. 393-399.

2. Marzano, R.J., D. Pickering, and J.E. Pollock, Classroom instruction that works: Research-based strategies for increasing student achievement. 2001: Ascd.

3. Felder, R. and B. Rebecca, Teaching and Learning STEM: A Practical Guide. 2016: Willey Bass.

4. Boylan-Ashraf, P.C., S.A. Freeman, and M.C. Shelley, A Case For a Reform in Teaching Introductory, Fundamental Engineering Mechanics Courses. 2014.

5. Brent, R. and R.M. Felder, A model for engineering faculty development. International Journal of Engineering Education, 2003. 19(2): p. 234-240. 
6. Felder, R.M. and R. Brent, The National Effective Teaching Institute: Assessment of impact and implications for faculty development. Journal of Engineering Education, 2010. 99(2): p. 121-134.

7. Henderson, C. and M.H. Dancy. Increasing the impact and diffusion of STEM education innovations. in Invited paper for the National Academy of Engineering, Center for the Advancement of Engineering Education Forum, Impact and Diffusion of Transformative Engineering Education Innovations, available at: http://www. nae. edu/File. aspx. 2011.

8. Sipos, Y., B. Battisti, and K. Grimm, Achieving transformative sustainability learning: engaging head, hands and heart. International Journal of Sustainability in Higher Education, 2008. 9(1): p. 68-86.

9. Henderson, C., et al., Designing educational innovations for sustained adoption: A how-to guide for education developers who want to increase the impact of their work. 2015.

10. Reichert, M. and M. Absher, Taking another look at educating African American engineers: The importance of undergraduate retention. Journal of Engineering Education, 1997. 86(3): p. 241-253.

11. Rogers, E.M., Diffusion of innovations. 2010: Simon and Schuster.

12. Reichheld, F.F., The one number you need to grow. Harvard business review, 2003. 81(12): p. 46-55.

13. Henderson, C. and M.H. Dancy, Impact of physics education research on the teaching of introductory quantitative physics in the United States. Physical Review Special Topics-Physics Education Research, 2009. 5(2): p. 020107.

14. Finelli, C., R. Kenyon, and D. Shanna, Factors that Influence Faculty Motivation of Effective Teaching Practices in Engineering, in Annual Conference - American Society for Engineering Education (ASEE), 2013. 2013.

15. Finelli, C.J., S.R. Daly, and K.M. Richardson, Bridging the Research-to-Practice Gap: Designing an Institutional Change Plan Using Local Evidence. Journal of Engineering Education, 2014. 103(2): p. 331361.

16. Marsh, H.W., Students' evaluations of university teaching: Dimensionality, reliability, validity, potential biases and usefulness, in The scholarship of teaching and learning in higher education: An evidence-based perspective. 2007, Springer. p. 319-383.

17. Shevlin, M., et al., The Validity of Student Evaluation of Teaching in Higher Education: Love me, love my lectures? Assessment \& Evaluation in Higher Education, 2000. 25(4): p. 397-405.

18. Benton, S. and W. Cashin, Student ratings of teaching: A summary of research and literature (IDEA Paper no. 50). Manhattan, KS: The IDEA Center. 2012.

19. Richardson, J.T.E., Instruments for obtaining student feedback: a review of the literature. Assessment \& Evaluation in Higher Education, 2005. 30(4): p. 387-415.

20. Prince, M., et al., Use of research-based instructional strategies in core chemical engineering courses. Chemical Engineering Education, 2013. 47(1): p. 27-37.

21. Henderson, C., M. Dancy, and M. Niewiadomska-Bugaj, Use of research-based instructional strategies in introductory physics: Where do faculty leave the innovation-decision process? Physical Review Special Topics-Physics Education Research, 2012. 8(2): p. 020104. 


\title{
Appendix 1:
}

\author{
Innovative Engineering Education \\ RCPIT, Shirpur, Maharashtra (India)
}

My RBIS Plan

Class: - SE (E \& TC)

Subject: - Solid State devices and circuit-I

\begin{tabular}{lll}
\hline $\begin{array}{c}\text { Faculty Name and } \\
\text { dept. }\end{array}$ & \multicolumn{1}{c}{ RBIS } & $\begin{array}{c}\text { Starting from (Probable } \\
\text { Date) }\end{array}$ \\
\hline $\begin{array}{l}* * * * * * * * * * \\
(\mathrm{E} \& \mathrm{TC})\end{array}$ & $\begin{array}{l}\text { Use of Animation videos for explaining } \\
\text { the working of different semiconductor } \\
\text { devices }\end{array}$ & Aug 2016 \\
& $\begin{array}{l}\text { Lab sessions - Students will solve } \\
\text { problems instead of doing procedure } \\
\text { oriented experiments }\end{array}$ & Sept 2016 \\
& & \\
& Ang 2016 \\
& & \\
\end{tabular}

